\title{
Meningeal carcinomatosis in solid tumors
}

\author{
Sandro José Martins', Carla Rameri Alexandre Silva de Azevedo², \\ Ludmilla Thomé Domingos Chinen ${ }^{3}$, Marcelo Rocha Sousa Cruz, \\ Marcos Aurélio Peterlevitz ${ }^{5}$, Daniel Luiz Gimenes ${ }^{4}$
}

\begin{abstract}
The involvement of the leptomeninges by metastatic tumors can be observed in solid tumors, in which case it is termed meningeal carcinomatosis (MC), and in lymphoproliferative malignant disease. It is more common in breast and lung cancer, as well as melanoma, with adenocarcinoma being the most frequent histological type. MC is usually a late event, with disseminated and progressive disease already present and, it is characterized by multifocal neurological signs and symptoms. Diagnosis is based on the evaluation of clinical presentation, cerebrospinal fluid and neuroimaging studies. The better systemic disease control is observed with new therapeutic agents, and the development of neuroimaging methods is responsible for the increasing incidence of such metastatic evolution. Intrathecal chemotherapy is generally the treatment of choice, although frequently palliative. Prognosis is guarded, although a higher performance status may indicate a subgroup of patients with a more favorable outcome.
\end{abstract}

Key words: meningeal carcinomatosis, cerebrospinal fluid, meninges, chemotherapy, metastases.

\section{Carcinomatose meníngea em tumores sólidos}

\section{RESUMO}

O acometimento leptomeníngeo por metástases tumorais pode ocorrer em tumores sólidos, sendo chamado de carcinomatose meníngea (CM), e também em doenças linfoproliferativas. Tumores de mama, pulmão e melanoma são os principais responsáveis pelos casos, e adenocarcinoma é a histologia mais frequentemente encontrada. A CM é um evento tardio na evolução da doença e caracteriza-se por sinais e sintomas neurológicos multifocais. O diagnóstico se faz pela avaliação conjunta do quadro clínico, neuroimagem e estudo do líquido cefalorraquidiano. O maior controle da doença sistêmica obtido com as novas modalidades terapêuticas e a baixa penetração de drogas no sistema nervoso central, aliados ao desenvolvimento nos métodos de neuroimagem observado nas últimas décadas, são fatores que respondem por um aumento na incidência desta apresentação. A quimioterapia intratecal é o tratamento de escolha, porém, frequentemente paliativo. O prognóstico é reservado, sendo que o melhor performance status pode selecionar um subgrupo de pacientes com melhor evolução.

Correspondence Marcelo Rocha Sousa Cruz Hospital A.C. Camargo Rua Professor Antônio Prudente 211 01509-900 São Paulo SP - Brasil E-mail: marcelorscruz@uol.com.br

Conflicts of interest

The authors report no conflicts of interest

Received 13 June 2011 Received in final form 22 June 2011 Accepted 1 July 2011
Palavras-Chave: carcinomatose meníngea, líquido cefalorraquidiano, meninges, quimioterapia, metástase.
The involvement of the leptomeninges by tumor metastases was recognized first by the Swiss pathologist Karl Joseph Ebert in $1870^{1}$; the term meningeal carcinomatosis (MC) being proposed by Siefert (1902) to describe the clinical condition.
${ }^{1} \mathrm{MD}$, Department of Oncology, Brasília DF, Brazil; ${ }^{2} \mathrm{MD}$, Department of Medical Oncology, Instituto de Medicina Integral de Pernambuco (IMIP), Recife PE, Brazil; ${ }^{P}$ PhD, Department of Medical Oncology, Hospital A. C. Camargo, São Paulo SP, Brazil; ${ }^{4} \mathrm{MD}$, Department of Medical Oncology, Hospital A.C. Camargo, São Paulo SP, Brazil; ${ }^{5}$ MD, Department of Neurology, Hospital A. C. Camargo, São Paulo SP, Brazil. 
It was considered rare at that time and the diagnosis was most commonly made post mortem ${ }^{2}$. In the last 40 years, it has been shown that $10 \%$ to $30 \%$ of patients with solid tumors develop neuraxis metastases, of which $4 \%$ to $15 \%$ represent $\mathrm{MC}^{3,4}$. Breast tumors, lung tumors and malignant melanomas are the principal tumors responsible for cases of MC. Adenocarcinoma is the most frequently encountered histological type $\mathrm{e}^{5}$.

In spite of accumulated understanding of the risk of $\mathrm{MC}$ and its clinical presentation, the occurrence of this condition remains underestimated in medical practice. Diagnosis is made difficult by the appearance of acute, subacute or late neurological changes due to the actual anticancer treatment; in many cases the initial investigations is limited to a cerebrospinal fluid (CSF) cytology, whose result often can be negative ${ }^{6}$.

\section{Epidemiology}

Meningeal carcinomatosis can be the first presentation of an as yet undetected primary cancer (6\%-38\%) or can occur during oncological treatment. The frequency of MC is estimated at $2 \%$ to $5 \%$ in breast cancer, $9 \%$ to $25 \%$ in lung cancer and in up to $23 \%$ of melanoma patients. There are indications that $\mathrm{MC}$ is a relatively late event in the evolution of solid tumors ${ }^{3,7,8}$. The better control of the systemic disease with newer therapeutic agents and poor penetration of these drugs into the central nervous system (CNS) are factors responsible for the increase in isolated relapses in the neuroaxis ${ }^{9-11}$. New forms of treatment for breast cancer, for example, such as taxanes, trastuzumab, and aromatase inhibitors have all contributed to the increased survival of these patient ${ }^{12}$, but at the same time the observation of cerebral metastases as well as MC as the initial site for recurrent disease has become more common ${ }^{10,13}$.

\section{Physiopathology}

$\mathrm{MC}$ is a heterogeneous clinical entity from the neuropathological viewpoint, with differences between isolated $\mathrm{MC}, \mathrm{MC}$ with invasion of the parenchyma of the CNS, and $\mathrm{MC}$ disseminated over the ventricular surface. From the clinical perspective it is more relevant to know the nature of the primary tumor (leukemia, lymphoma, or solid tumor) as well as the stage of the disease in which $\mathrm{MC}$ is diagnosed-as an isolated relapse, together with mild systemic disease, or in the context of widely disseminated metastases.

The meningeal involvement by the tumor can be due to hematological invasion of the subarachnoid space or cerebral ventricles, with later spread to the CSF, as happens in germinomas, ependymomas, retinoblastomas, optic nerve gliomas, pilocytic astrocytomas, and primitive neuroectodermal tumors. Conversely, the tumor may go directly to the dura mater, pia mater, or the ependymal structures, allowing for local tumor growth, as happens in nasopharyngeal carcinomas, cranial osteosarcomas, superficial cortical cerebral metastases, and in bony metastases with epidural invasion. Direct extension can also occur from tumor deposits and/or centripetal migration of tumor cells by the perineural and perivascular spaces, or following the cranial or radicular nerve pathways, as in adenocystic carcinomas ${ }^{14,15}$. This mechanism seems implicated as well in MC associated with the use of bevacizumab for the treatment of lung cancer ${ }^{16}$. The distribution of the leptomeningeal lesions is influenced by the CSF circulation, being more common in the lumbar region where the CSF flow is reduced.

\section{Clinical presentation}

Symptoms of MC result from multiple interrelated events: obstruction of CSF flow causing hydrocephalus; neuronal dysfunction due to the metabolic competition between the tumor cells and normal cells for nutrients; neoplastic invasion of the Virchow-Robin spaces; and vascular alterations caused by the tumor growth itself. Typically there are multifocal neurological symptoms and signs at multiple levels of the neuraxis. Strictly speaking, the meningeal involvement can be classified into lesions of the cerebral hemispheres (present in 15\% of patients), lesions of the spinal medulla (60\%), and lesions of cranial nerves $(35 \%)^{15}$.

The complaints of the patient are usually the first clue to the subarachnoid invasion by tumor cells. Published case series have not shown that different types of cancer present differently. There has been consensus as regards the multifocal aspects (cerebral, cranial and radicular nerve involvement) in the clinical history and physical exam ${ }^{14,15}$.

Initial symptoms include headache, nausea and vomiting, convulsion, lower back pain, radicular nerve pain, paresthesias, gait disturbances, and defects in mental functioning. In a recent series of 60 patients with $\mathrm{MC}$ associated with breast cancer, $55 \%$ of patients had headache, $50 \%$ had cranial nerve paralysis, $23 \%$ had intracranial hypertension, $20 \%$ had vertigo and $12 \%$ had convulsions ${ }^{13}$.

Involvement of the cerebral hemispheres can be accompanied by headache, with nausea, vomiting and vertigo. Eventually, it can lead to complex dysfunction of the cerebral trunk, ophthalmoplegias, cerebral infarcts, and diencephalic syndromes ${ }^{14}$. Nuchal rigidity is infrequent (15\% of cases) and the presence of signs such as aphasia, hemiparesia, or visual alterations are also described ${ }^{14,15}$. While mental changes, memory loss, cognitive disturbances, psychiatric disturbances and convulsions may be present, focal isolated defects are rare. Non communicating hydrochephalus is uncommon.

Signs and symptoms of cranial nerve involvement 
are commonly found on the initial exam and tend to progress with advancing disease. Most common symptoms are diplopia, hypoacusia, amaurosis and facial hypoesthesia. Generally there is variable involvement of the optic nerves, the oculomotor, trochlear, trigeminal, abduscens, facial and hypoglossal nerves; vestibulocochlear nerve involvement is rare ${ }^{17-19}$. Dysfunction of cranial pairs in patients with cancer is not necessarily associated with $\mathrm{MC}$, and lesions of the cranial base; soft tissue metastases, extra cranial infiltration of nervous structures, collateral effects of anticancer therapy, and paraneoplastic syndromes should be considered in the differential diagnosis.

Gait alterations can be caused by cerebellar dysfunction or by peripheral caudal equinal lesions. Involvement of the lumbosacral nerve roots is common in $\mathrm{MC}$, and brings with it variable motor deficits. On examination, dysfunctions of the inferior motor neurons with muscular weakness, accompanied by loss of reflexes and hypoesthesia in the corresponding dermatomes are often observed. In a few cases, a mono or oligosegmental distribution can mimic degenerative diseases of the intervertebral discs, confusing the diagnosis. The symptoms may suggest a cauda equina lesion with flaccid paralysis and walking difficulties. Intestinal dysfunction and neurogenic bladder are findings infrequently found in MC. Signs of radicular involvement include arreflexia, asymmetry of nerve root involvement, muscular weakness, atrophy, paresthesias and dysesthesias ${ }^{14}$. Signs and symptoms of oligoradicular cervico-braquial nerve involvement can occur in breast cancer, initiated by radicular dysesthesias followed or not by painful paresias of the mononeuritic type. In the thoracic region, the most common finding involves bilaterally irradiating pain, often associated with local bony destruction. Multiradicular involvement is uncommon in solid tumors, but occasionally present as a painful ascending paralysis, similar to acute polyradiculopathy, a pattern also found in leukemias and lymphomas.

\section{Additional examinations}

The diagnosis of MC is made by the combined picture offered by the clinical examination, neuroimaging studies, and CSF results ${ }^{20}$. The presence of neoplastic cells in the CSF is the most useful finding to confirm the diagnosis. Although this finding in the initial examinations has no prognostic value ${ }^{6,21}$ it is a very important finding after treatment ${ }^{21}$. Nuclear medicine studies are useful in treatment planning.

Neuroimaging studies - Computerized Tomography (CT) with contrast use and Magnetic Resonance Imaging (MRI) allow identification of the pathological processes involved in leptomeninges. MRI, due to its technical advantages, is considered the standard choice for patients with a clinical presentation suggestive of $M C^{21}$. Nevertheless, in spite of the superiority of MRI over $\mathrm{CT}$, both methods have a high false negative rate (MRI 30\% and CT 58\%) ${ }^{22}$. With the use of paramagnetic contrast, any irritating stimulus to the meninges can be identified by hypercaptation, either circumscribed or diffuse. This includes intradural infiltration by tumor, focal neoplastic infiltration, local isquemia, infection, inflammation, granulomas, venous thrombosis, radiotherapy-induced lesions, chemotherapy irritating stimuli, heavy metals, hypoxia, subarachnoid hemorrhage, and trauma ${ }^{23,24}$. However, there has been a suggestion the MRI is less accurate, diagnostically speaking, in patients treated systemically with bevacizumab, due to the biological effects of this treatment ${ }^{16}$.

The anatomical and functional basis of the meningeal enhancement is due to the increased capture of contrast by the dura mater. This makes it more difficult to distinguish the leptomeningeal enhancement, except in areas of major collection of CSF fluid near the base of the cranium and the major fissures. As the dura mater is thick, contrast medium does not penetrate the subarachnoid space up to the leptomeninges; thus any enhancement of the arachnoid and pia mater is pathologic. Penetration of the CSF barrier is a sign of advanced disease, and tumor invasion of the arachnoid villae is associated with CSF circulation disturbances. The ensuing reduction in its reabsorption results in communicating hydrocephalus, which should be considered as an indirect confirmation of MC

In the oncologic patient with clinical suspicions of MC, MRI findings will confirm or establish the diagnosis of MC. Suggestive findings include: nerve thickening, linear enhancement of the leptomeninges, superficial multiple cerebral metastases, and intradural nodules. Nevertheless, in patients without a previous diagnosis of cancer, who present a meningeal or subarachnoid space enhancement, MC is a possible diagnosis, and these findings require a pathologic diagnosis. Neurosarcoidosis, neuroschistosomiasis, chronic meningitis, Gullain-Barre syndrome, and previous lumbar puncture can also produce gadolinium enhancement of MRI. In the case of CSF lumbar punctures, a linear enhancement may occur not only at the puncture site but also along the neuroaxis, lasting for weeks to months, accompanied by headache due to low CSF pressure in some patients. Thus, patients suspected of MC should have neuroimaging exams before the CSF lumbar puncture, which will avoid artifacts on the exam.

CSF cytology - Demonstration of neoplastic cells in the CSF is moderately sensitive for the diagnosis of MC, but $15-20 \%$ of suspected clinical cases will not be confirmed by this method. Positive cytology for can- 
cerous cells will increase with the number of punctures, but the false negative rate is still high, due to the similarity between tumor cells and ependymal cells, contamination by blood due to multiple puncture, few tumor cells in the collected specimen and inadequate preparation of the sample. It must be remembered also that when the tumor infiltration is confined to the cranium and the dura mater, neoplastic cells will not be found in the CSF.

Two cytological patterns may be seen with variable overlapping between them: the first consists of the presence of groups of cells which occasionally allow for the histological identification of the original tumor as seen in primary cerebral tumors (medulloblastoma, ependymomas, glioblastomas and pineoblastomas) and isolated metastases from solid tumors. The second type is characterized by isolated tumor cells with minimal aggregation, without characteristics of the original tumor architecture, such as seen when there is extensive involvement of the subarachnoid space. In these cases, the CSF cytology is useful only for confirmation of the presence of neoplastic cells, and does not serve for histological definition. Leukemia and lymphoma cells retain original characteristics of the tumor and the severity of the disease is not reflected necessarily in the CSF cellularity, which can vary from normal to very elevated.

Viral infections of the CNS can produce false positive cytology often making the distinction of lymphomatous infiltrations difficult, which does not happen in carcinomas or melanomas. Technical aspects which influence the cytomorphologial exam of the CSF should also be considered. It is preferable that the specimen be processed within an hour after collection. Cytocentrifuge use or sedimentation methods allow for better retrieval of cellular elements without artifacts ${ }^{25,26}$. Staining by May-Grünwald-Giemsa, usual in hematology, has advantages over the Papanicolou stain in terms of delineating nuclear structures and cytoplasmic limits, and thus is the method of choice. Mitotic figures and polyploidy are helpful in differentiating neoplastic cells and normal ependymal cells eventually present. However, their presence is neither a necessary nor sufficient diagnostic criteria in all cases. In epithelial tumors, usually the presence of few cell groups with their typical aspects is sufficient to confirm the diagnosis of MC. Moreover, in children, the presence of proliferative cells in groups is not always evidence of malignancy.

In patients with $\mathrm{MC}$, only $50 \%$ will present initial positive cytology, but this will increase to $90 \%$ positivity after the third exam. As well as the repetition of the exam, CSF collected at different levels of the neuraxis could be helpful in obtaining a cytological diagnosis. Noteworthy, a CSF protein levels can vary according to puncture site (lumbar or suboccipital) even in the absence of CSF ob- struction $^{15}$. A low CSF glucose level $(<60 \mathrm{mg} / \mathrm{dl})$ and high protein level $(>50 \mathrm{mg} / \mathrm{dl})$ are additional parameters which contribute to confirming the diagnosis.

Tumor markers - The identification of biochemical tumor markers in the CSF with a potential diagnostic value has been a challenge. The following markers have been studied: beta-glicuronidase, lactate dehydrogenase 5, beta2-microglobuline, alfa-fetoprotein, carcinoembryonic antigen, carbohydrate antigen $15-3$, prostate specific antigen, tissue polypeptide antigen, vascular endothelial growth factor, myelin basic protein, and the $\mathrm{BB}$ form of creatinine kinase ${ }^{27-33}$. Apart from being informative in a variable number of situations, none of these markers have definitely shown an increase in the diagnostic yield compared to the cytological exam.

The selection of tumor markers for use in CSF studies should be guided by the patient's type of primary tumor, or by an observed serial elevation of these markers in the patient in question. The CSF marker of interest should be tested simultaneously with that of the serum, to eliminate the possibility of passive diffusion. When there has been no blood brain barrier (BBB) disruption, the penetration of tumor markers is minimal. Yet when the CSF marker levels are disproportionately high and the $\mathrm{BBB}$ is intact, the markers may be being produced in the subarachnoid space by the tumor metastases ${ }^{34}$.

Immunohistochemistry - Monoclonal antibodies to mark tumors are not very helpful in solid tumors, due to the scarce cellularity and frequent dedifferentiation observed. However, in lymphomas and leukemias they may reveal the clonal nature of the lymphocytic infiltrates, without other malignant characteristics.

Molecular biology - Amplification of tumor specific gene sequences by polimerase chain reaction may be used to detect minimal quantities of neoplastic cells in the CSF, in situations in which conventional cytology is inconclusive ${ }^{35}$. This method can be used when the genetic alterations in the tumor are known, as in some forms of leukemais and lymphomas, but has no application in solid tumors.

Nuclear medicine - Flow studies of the CSF using radionucleotides (DTPA-Índio-111) are more sensitive than either MRI or CT in the anatomo-functional evaluation of the different CSF compartments. Its importance is well known in the identification of compartmentalization of the CSF and in obstructions to its flow. These findings are common in $\mathrm{MC}$ and critical in determining the distribution of CSF medications and also in the prognosis for these patients ${ }^{36,37}$. Radioisotope ventriculography is a secure, physiologic diagnostic method, based on the passive transport of the radiotracer by the ventricular system, subarachnoid cerebral and spinal space

About $50 \%$ of patients with MC will show alterations 
in the CSF flow, most commonly at the base of the skull, cerebral convexities, and in the subarachnoid space of the terminal cone of the medulla and the cauda equina. It is thought that the compartmentalization of the CSF thus detected is due to the presence of small occlusions due to tumor fragments too small to be seen on MRI or $\mathrm{CT}^{38}$.

\section{Treatment}

Treatment of $\mathrm{MC}$ is frequently unable to provide lasting clinical benefit for the majority of patients. This is due to the limited scope of antineoplastic agents that can be administered safely by the intrathecal route, to extension of the basic disease and previous tumor exposure to antineoplastic agents with probable selection of chemoresistent clones, and the presence of flow obstruction of the CSF. Notwithstanding these problems, treatment can often alleviate symptoms with resultant increase in survival. The principal therapeutic modalities available in oncology, surgery, chemotherapy and radiotherapy, all have a part to play in the palliative treatment of patients with MC.

Surgery - Intrathecal chemotherapy can be administered by lumbar puncture or directly via intraventricular catheter. Patients with MC benefit from the implantation of a reservoir for intraventricular chemotherapy administration such as Salmon-Rickham and Ommaya devices, which can be safely implanted under general anesthesia or by local block, preferably with stereotactic techniques ${ }^{39}$. Use of reservoirs permits ambulatory treatment, which is more comfortable for the patient, permits the maintenance of treatment even with low platelet levels and assures that the medication is distributed most efficiently within the subarachnoid space. One comparative study of intraventricular versus lumbar delivery showed an advantage of the intraventricular delivery route, in view of time taken for drug diffusion into the CSF. This is particularly important when using drugs such as methotrexate, which have a short half-life ${ }^{40}$.

A ventriculoperitoneal shunt for the symptomatic alleviation of intracranial hypertension, present in cases of communicating hydrocephalus may also contribute to palliation ${ }^{5}$. In this scenario, with intrathecal chemotherapy programmed, it is necessary to use a shunt with a valve to control the opening, such that it can remain shut for 6-12 hours after treatment to allow for diffusion and circulation of the medication.

Radiotherapy - Radiotherapy has a general and effective palliative role in the symptomatic control of MC. Pain, particularly radicular, can be rapidly alleviated with radiation treatment. It is administered in the symptomatic area of the neuraxis, occasionally including areas of major involvement as found on imaging studies, which are still asymptomatic
It is not uncommon for the symptoms to be worst in areas in which there is little radiological evidence for massive tumor involvement. Consequently, patients with pain and paresias in the lower leg need cauda equine irradiation, while those with alterations of the cranial nerves may require irradiation to the entire cranium or just to the skull base ${ }^{41}$.

Focal palliative radiotherapy of the neuraxis can be done safely and effectively in short periods using a dose of $30 \mathrm{~Gy}$ in ten fractions. Although this treatment will produce a significant analgesic effect along with stabilization of the neurological deficits, neurological recover is unlikely. Autopsies have shown that even with destruction of the tumor cells, there still are lesions in the nerve roots and cranial nerves, either as demyelination and axonal lesion, resulting of treatment, or produced by the underlying disease process itself.

$\mathrm{MC}$ patients have widespread dissemination of tumor in the subarachnoid space, although they may have only focal symptoms. Palliative irradiation of the entire neuraxis, however, is rarely considered, due to its excessive hematologic toxicity, and to the fact that there is no proof to show that it can either prevent or retard neurological deterioration.

Palliative radiation therapy is best undertaken soon after the diagnosis of MC. In addition to indications for symptom control, radiotherapy can also be applied to CSF obstructions. This has been shown to be effective in restoring flow and allowing for a more adequate distribution of intrathecal chemotherapy, with resultant clinical benefit ${ }^{37}$.

Chemotherapy - Intrathecal (IT) chemotherapy is one of the most commonly used treatments in MC. Theoretically its use gives the best exposure to the chemotherapy, because the impermeability of the BBB limits the availability of drugs delivered systemically. Some studies have suggested a better clinical outcome using intrathecal drugs such as methotrexate, cytaribine, and thiotepa. However up to $30 \%$ of patients were excluded from analysis as they did not have the functional capacity to receive treatment ${ }^{42,43}$. Patients with low functional capacity (defined here as ECOG $>3$ or Karnofsky $<50 \%$ ) do not benefit from palliative antineoplastic therapy ${ }^{44}$.

Effective intrathecal chemotherapy presupposes a homogeneous passive diffusion of the agent along the subarachnoid space and ventricular system, giving good exposure of the tumor cells to the therapeutic drug levels. Patients with CSF flow alterations are most likely to have a therapeutic failure and thus a more guarded prognosis ${ }^{43}$. Reestablishment of adequate CSF flow seems to increase both the efficacy of the intrathecal chemotherapy and the prognosis ${ }^{37}$. The limited benefit of this type of therapy is due both to the poor penetration of 
Table. Response rate and survival with intrathecal chemotherapy.

\begin{tabular}{|c|c|c|c|c|c|}
\hline \multirow{2}{*}{$\frac{\text { Study }}{\text { Grossman et al. }{ }^{47}}$} & \multirow[t]{2}{*}{$\mathrm{n}$} & \multicolumn{2}{|c|}{ Response rate* } & \multicolumn{2}{|c|}{ Survival (weeks) } \\
\hline & & & & & \\
\hline MTX & 28 & 0 & & 15.9 & $p=0.36$ \\
\hline Thiotepa & 24 & 0 & & 14.1 & \\
\hline \multicolumn{6}{|l|}{ Glantz et al. ${ }^{48}$} \\
\hline Liposomal ARAC & 31 & 8 & $p=0.76$ & 15 & $p=0.15$ \\
\hline MTX & 30 & 6 & & 11 & \\
\hline \multicolumn{6}{|l|}{ Hitchins et al. ${ }^{49}$} \\
\hline MTX & 23 & 14 & $p>0.1$ & 12 & $p=0.084$ \\
\hline MTX + ARAC & 20 & 9 & & 7 & \\
\hline
\end{tabular}

*Neurological evaluation and/or CSF cytology. MTX: methotrexate; ARAC: Cytarabine; $\mathrm{n}$ : number of cases.

drugs into the tumor as well as to the limited armamentarium of therapeutic agents available. While it is possible that the anticancer agent may passively infiltrate a few millimeters into the tumors, this seems to be insufficient for a major cytotoxic effect ${ }^{45}$.

Therapeutic protocols for MC use antimetabolites (methotrexate and cytarabine) with or without an alkylating agent (thiotepa) ${ }^{43}$. These antineoplastic drugs were introduced into clinical practice more than 50 years ago. They are moderately active for the treatment of neoplastic foci of leukemias, lymphomas, choriocarcinomas and breast cancer, although they are not considered effective for the majority of solid tumors ${ }^{42,46}$. In fact, there has been no report of superiority among chemotherapeutic agents in the past several decades. Table shows the response rates and survival times found in randomized studies which evaluated intrathecal chemotherapy use. Moreover, there is no unequivocal evidence to show that intrathecal chemotherapy gives the same increase in survival as that given by optimal systemic therapy.

The increasing number of patients with metastatic cancer who develop MC at some point in their disease gives good reason for investigation of regional chemotherapy with new antineoplastic agents. Promising initial results have been obtained using mafosfamide, lyposomal cytarabine, trastuzumabe, rituximabe, 5-fluoro-2'deoxiuridine, topotecan e nimustine ${ }^{47-54}$.

Conventional systemic treatment has variable penetration in the subarachnoid space depending upon the extent of the breakdown of the BBB due to tumor implants and the subjacent inflammatory phenomenon. Regardless of the BBB drug penetration, data shows that systemic chemotherapy response has a positive impact on the survival of patients with $\mathrm{MC}^{55}$. A randomized trial compared intrathecal and systemic chemotherapy with systemic treatment alone in breast cancer patients with MC. The median survival was 18.3 weeks in the IT arm and 30.3 weeks in the non-IT arm, although no statistical significance was achieved. Neurological complications related to treatment occurred more commonly IT $\operatorname{arm}(47 \% \text { vs } 6 \%)^{56}$. Despite a poor therapeutic index for use in solid tumors, methotrexate and cytarabine in high doses as used occasionally in high grade lymphomas and leukemias, give therapeutic CSF levels. This raises the question as to whether systemic chemotherapy should be considered a critical part of the multimodal approach of MC patients.

\section{Complications of treatment}

The appearance of new sign and symptoms in a patient with $\mathrm{MC}$ is often a diagnostic problem, especially if the CSF cytology is negative. Recurrence, side effects of treatment and other complications are diagnostic possibilities which require different approaches.

Treatment, in general is safe. Adverse effects include headache, vomiting, mucositis and chemical meningitis. Late adverse events are seen in some patients who received intrathecal prophylaxis as a part of curative protocols. Collateral effects such as leukoencephalopathy, dementia and ataxia, may also occur frequently from neuraxis radiation.

Chemical meningitis secondary to intrathecal treatment can occur in 20\%-40\% of cases, and presents with headache, mental confusion, delirium and acute pain radiating into the extremities ${ }^{47-49}$. CSF exam cytology in these cases shows an increase in cellularity over 24 hours due to polymorphonuclear leukocytes. Use of concomitant glucocorticoids with the chemotherapy reduces the risk and intensity of the inflammation. There is a report of improving subacute myelopathy caused by intrathecal methotrexate when high doses of S-adenosilmethionine (200 mg, iv three times per day), folinic acid (20 mg, iv four times per day), cyanocobalamin (100 mg, once daily) and methionine (5 g, once daily orally) were supplemented ${ }^{56}$. Acute paraplegia is a rare complication described with use of triple therapy including methotrexate, cytarabine, and thiotepa. This clinical picture must be differentiated from subdural hematoma of the spinal medulla, a clinical condition which sometimes occurs in patients with MC. Other complications of intrathecal chemotherapy include infections at the puncture site, bacterial meningitis, and bleeding from a dislocated intraventricular catheter. Radiotherapy can produce a leukoencephalitis with acute or delayed symptoms. The risk for this complication is higher with the concomitant use of intrathecal methotrexate.

\section{Prognosis}

Patients with MC have a guarded prognosis. Disease progression can occur a few weeks or months after 
starting therapy, presenting as a worsening of initial complaints and neurological changes, and with new clinical symptoms and signs. Generally there is neuraxis involvement at multiple levels, with a rapid clinical deterioration and median survival of four to six weeks. Patients with malignant blood diseases generally have better clinical and functional capacities for a longer time and may be in remission with $\mathrm{MC}$ for months to years. Among solid tumors, breast cancer cases respond the best to treatment, with a median survival of six month $s^{57-61}$. The prognosis is determined by the extension of the systemic disease, resistance to therapy which occurs after multiple previous treatments, as well as progressive neurological dysfunction.

\section{REFERENCES}

1. Eberth KJ. Zur Entwicklung des Epithelioma (Cholesteatoms) der Pia und der Lu. Arch Pathol Anat Physiol Klin Medizin 1870;49:51-63.

2. Siefert E. Über die multiple Karzinomatose des Zentralnervensystem. Münch Med Woch 1902;49:826-828.

3. Weil RJ, Palmieri DC, Bronder JL, Stark AM, Steeg PS. Breast cancer metastasis to the central nervous system. Am J Pathol 2005;167:913-920.

4. Aragon-Ching JB, Zujewski JA. CNS metastasis: an old problem in a new guise. Clin Cancer Res 2007;13:1644-1647.

5. Chamberlain MC. Neoplastic meningitis. Curr Neurol Neurosci Rep 2008; 8:249-258.

6. Glantz MJ, Walters BC. Diagnosis and outcome measures in trials for neoplastic meningitis: a review of the literature and clinical experience. Neurosurg Focus 1998;4:e4.

7. Slimane K, Andre F, Delaloge S, et al. Risk factors for brain relapse in patients with metastatic breast cancer. Ann Oncol 2004;15:1640-1644.

8. Lima VS, Fernandes Jr AS, Fonseca RP, Lima SSS. Carcinomatose meníngea nos tumores sólidos. Rev Bras Cancerol 2003;49:245-251.

9. Kosmas C, Malamos NA, Tsavaris NB, et al. Isolated leptomeningeal carcinomatosis (carcinomatous meningitis) after taxane-induced major remission in patients with advanced breast cancer. Oncology 2002;63:6-15.

10. Bendell JC, Domchek SM, Burstein HJ, et al. Central nervous system metastases in women who receive trastuzumab-based therapy for metastatic breast carcinoma. Cancer 2003;97:2972-2977.

11. Lin C, Turner S, Gurney H, Peduto A. Increased detections of leptomeningeal presentations in men with hormone refractory prostate cancer: an effect of improved systemic therapy? J Med Imaging Radiat Oncol 2008;52:376-381.

12. Andre F, Slimane $K$, Bachelot $T$, et al. Breast cancer with synchronous metastasis: trends in survival during a 14-year period. J Clin Oncol 2004;22: 3302-3308.

13. de Azevedo CRAS, Cruz MRS, Chinen LTD, et al. Meningeal carcinomatosis in breast cancer: prognostic factors and outcome. J Neurooncol 2011. DOI 10.1007/s11060-010-0524-y.

14. Wolfgang G, Marcus D, Ulrike S. LC: clinical syndrome in different primaries. J Neurooncol 1998:38:103-110.

15. Chamberlain MC. Neoplastic meningitis. J Clin Oncol 2005;23:3605-3613.

16. Kleinschmidt-Demasters BK, Damek DM. The imaging and neuropathological effects of Bevacizumab (Avastin) in patients with leptomeningeal carcinomatosis. J Neurooncol 2010;96:375-384.

17. Cantillo R, Jain J, Singhakowinta A, Vaitkevicius VK. Blindness as initial manifestation of meningeal carcinomatosis in breast cancer. Cancer 1979:44:755-757.

18. Koda H, Kimura Y, lino Y, Eishi Y, Murakami Y, Kitamura K. Bilateral sudden deafness caused by diffuse metastatic leptomeningeal carcinomatosis. Otol Neurotol 2008;29:727-729.

19. Goyault G, Kremer S, Martin E, Riehm S, Dietemann JL, Veillon F. Leptomeningeal carcinomatosis and sensorineural hearing loss: correlation of labyrinthine enhancement patterns with symptoms. J Neuroradiol 2009; 36:98-101.

20. Chamberlain MC, Glantz M, Groves MD, Wilson WH. Diagnostic tools for neoplastic meningitis: detecting disease, identifying patient risk, and determining benefit of treatment. Semin Oncol 2009;36(Suppl):S35-S45.

21. Chamberlain MC, Johnston SK. Neoplastic meningitis: survival as a function of cerebrospinal fluid cytology. Cancer 2009;115:1941-1946.

22. Chamberlain MC, Sandy AD, Press GA. Leptomeningeal metastasis. A comparison of gadolinium-enhanced MR and contrast-enhanced CT of the brain. Neurology 1990;40:435-438.

23. Chamberlain MC. Comparative spine imaging in leptomeningeal metastases. J Neurooncol 1995;23:233-238.

24. Gomori JM, Heching N, Siegal T. Leptomeningeal metastases: evaluation by gadolinium enhanced spinal magnetic resonance imaging. J Neurooncol 1998;36:55-60.

25. Tutuarima JA, Hische EA, van der Helm HJ. An improved method for the concentration of cerebrospinal fluid cells by suction tip and sedimentation chamber. J Neurol Sci 1979;44:61-67.

26. Brandão CA, Dos Reis Filho JB. [Differential counting of cerebrospinal fluid cells by the facilitated gravitational sedimentation method. 2. The concept of normality]. Arq Neuropsiquiatr 1984;42:140-145.

27. Shuttleworth $E$, Allen N. CSF beta-glucuronidase assay in the diagnosis of neoplastic meningitis. Arch Neurol 1980;37:684-687.

28. Yap BS, Yap HY, Fritsche HA, Blumenschein G, Bodey GP. CSF carcinoembryonic antigen in meningeal carcinomatosis from breast cancer. JAMA 1980;244:1601-1603.

29. Bach F, Bach FW, Pedersen AG, Larsen PM, Dombernowsky P. Creatine kinase-BB in the cerebrospinal fluid as a marker of CNS metastases and leptomeningeal carcinomatosis in patients with breast cancer. Eur J Cancer Clin Oncol 1989;25:1703-1709.

30. Nakagawa H, Kubo S, Murasawa A, et al. Measurements of CSF biochemical tumor markers in patients with meningeal carcinomatosis and brain tumors. J Neurooncol 1992;12:111-120.

31. Gauchez AS, Pez E, Boutonnat J, et al. [Early detection of leptomeningeal metastasis in patients with metastatic breast carcinoma: validation of CA 15-3 measurement in cerebrospinal fluid]. Ann Biol Clin (Paris) 2007;65:653-658.

32. Groves MD, Hess KR, Puduvalli VK, et al. Biomarkers of disease: cerebrospinal fluid vascular endothelial growth factor (VEGF) and stromal cell derived factor (SDF)-1 levels in patients with neoplastic meningitis (NM) due to breast cancer, lung cancer and melanoma. J Neurooncol 2009;94: 229-234.

33. Orphanos G, loannidis G, Michael M, Kitrou G. Prostate-specific antigen in the cerebrospinal fluid: a marker of local disease. Med Oncol 2009;26: 143-146.

34. Corsini E, Bernardi G, Gaviani P, et al. Intrathecal synthesis of tumor markers is a highly sensitive test in the diagnosis of leptomeningeal metastasis from solid cancers. Clin Chem Lab Med 2009;47:874-879.

35. Rhodes $\mathrm{CH}$, Glantz MJ, Glantz L, et al. A comparison of polymerase chain reaction examination of cerebrospinal fluid and conventional cytology in the diagnosis of lymphomatous meningitis. Cancer 1996;77: 543-548.

36. Chamberlain MC, Kormanik P, Jaeckle KA, Glantz, M. 111 Indium-diethylenetriamine pentaacetic acid CSF flow studies predict distribution of intrathecally administered chemotherapy and outcome in patients with leptomeningeal metastases. Neurology 1999;52:216-217.

37. Chamberlain MC, Kormanik PA. Prognostic significance of 111 indiumDTPA CSF flow studies in leptomeningeal metastases. Neurology 1996; 46:1674-1677.

38. Mason WP, Yeh SD, DeAngelis LM. 111 Indium-diethylenetriamine pentaacetic acid cerebrospinal fluid flow studies predict distribution of intrathecally administered chemotherapy and outcome in patients with leptomeningeal metastases. Neurology 1998;50:438-444.

39. Sandberg DI, Bilsky MH, Souweidane MM, Bzdil J, Gutin PH. Ommaya reservoirs for the treatment of leptomeningeal metastases. Neurosurgery 2000:47:49-54

40. Glantz MJ, Van Horn A, Fisher R,Chamberlain MC. Route of intracerebrospinal fluid chemotherapy administration and efficacy of therapy in neoplastic meningitis. Cancer 2010;116:1947-1952.

41. Feyer P, Sautter-Bihl ML, Budach W, et al. DEGRO Practical Guidelines for palliative radiotherapy of breast cancer patients: brain metastases and leptomeningeal carcinomatosis. Strahlenther Onkol 2010;186: 63-69.

42. Siegal T. Leptomeningeal metastases: rationale for systemic chemotherapy or what is the role of intra-CSF-chemotherapy? J Neurooncol 1998, 38:151-157.

43. Grossman SA, Finkelstein DM, Ruckdeschel JC, Trump DL, Moynihan T, Et- 
tinger DS. Randomized prospective comparison of intraventricular methotrexate and thiotepa in patients with previously untreated neoplastic meningitis. Eastern Cooperative Oncology Group. J Clin Oncol 1993; 11:561-569.

44. Chamberlain MC, Johnston SK, Glantz MJ. Neoplastic meningitis-related prognostic significance of the Karnofsky performance status. Arch Neurol 2009;66:74-78.

45. Motl S, Zhuang Y, Waters CM, Stewart CF. Pharmacokinetic considerations in the treatment of CNS tumours. Clin Pharmacokinet 2006;45:871-903.

46. Bokstein F, Lossos A, Siegal T. Leptomeningeal metastases from solid tumors: a comparison of two prospective series treated with and without intra-cerebrospinal fluid chemotherapy. Cancer 1998;82:1756-1763.

47. Grossman SA, Finkelstein DM, Ruckdeschel JC, et al. Randomized prospective comparison of intraventricular metotrexate and thiotepa in patients with previously untreated neoplastic meningitis. J Clin Oncol 1993;11: 561-569.

48. Glantz MJ, Jaeckle KA, Chamberlain MC, et al. A randomized controlled trial comparing intrathecal sustained-release cytarabine (DepoCyt) to intrathecal methotrexate in patients with neoplastic meningitis from solid tumors. Clin Cancer Res 1999;5:3394-3402.

49. Hitchins RN, Bell DR, Woods RL, et al. A prospective randomized trial of single-agent versus combination chemotherapy in meningeal carcinomatosis. J Clin Oncol 1987;5:1655-1662.

50. Nakagawa H, Yamada M, Maeda N, Iwatsuki K, Hirayama A, Ikenaka K. Clinical trial of intrathecal administration of 5-fluoro-2'-deoxyuridine for treatment of meningeal dissemination of malignant tumors. J Neurooncol 1999:45:175-183.

51. Laufman LR, Forsthoefel KF. Use of intrathecal trastuzumab in a patient with carcinomatous meningitis. Clin Breast Cancer 2001;2:235.
52. Fleischhack G, Jaehde U, Bode U. Pharmacokinetics following intraventricular administration of chemotherapy in patients with neoplastic meningitis. Clin Pharmacokinet 2005;44:1-31.

53. Stemmler HJ, Schmitt M, Harbeck N, et al. Application of intrathecal trastuzumab (Herceptintrade mark) for treatment of meningeal carcinomatosis in HER2-overexpressing metastatic breast cancer. Oncol Rep 2006; 15:1373-1377.

54. Antonini G, Cox MC, Montefusco E, et al. Intrathecal anti-CD20 antibody: an effective and safe treatment for leptomeningeal lymphoma. J Neurooncol 2007;81:197-199.

55. Rudnicka H, Niwin'ska A, Murawska M. Breast cancer leptomeningeal metastasis: the role of multimodality treatment. J Neurooncol 2007;84:57-62.

56. Boogerd W, van den Bent MJ, Koehler PJ, et al. The relevance of intraventricular chemotherapy for leptomeningeal metastasis in breast cancer: a randomized study. Eur J Cancer 2004;40:2726-2733.

57. Ackermann R, Semmler A, Maurer GD, et al. Methotrexate-induced myelopathy responsive to substitution of multiple folate metabolites. J Neurooncol 2010;97:425-427.

58. Chamberlain MC, Kormanik PR. Carcinomatous meningitis secondary to breast cancer: predictors of response to combined modality therapy. J Neurooncol 1997;35:55-64.

59. Boogerd W, Hart AA, van der Sande JJ, Engelsman E. Meningeal carcinomatosis in breast cancer. Prognostic factors and influence of treatment. Cancer 1991;67:1685-1695.

60. Harstad L, Hess KR, Groves MD. Prognostic factors and outcomes in patients with leptomeningeal melanomatosis. Neuro Oncol 2008;10:1010-1018.

61. Bruna J, Gonzalez L, Miro J, Velasco R, Gil M, Tortosa A. Leptomeningeal carcinomatosis: prognostic implications of clinical and cerebrospinal fluid features. Cancer 2009;115:381-389. 